\title{
Adiponectin isoforms: a potential therapeutic target in rheumatoid arthritis?
}

Frommer, Klaus W ; Schäffler, Andreas ; Büchler, Christa ; Steinmeyer, Jürgen ; Rickert, Markus ; Rehart, Stefan ; Brentano, Fabia ; Gay, Steffen ; Müller-Ladner, Ulf ; Neumann, Elena

\begin{abstract}
OBJECTIVES: Several clinical studies have suggested the adipocytokine adiponectin is involved in the progression of rheumatoid arthritis (RA). From this point of view, adiponectin might present a new therapeutic target. However, as adiponectin also exerts beneficial effects in the human organism, a strategy that would allow its detrimental effects to be abolished while maintaining the positive effects would be highly favourable. To elucidate such a strategy, the authors analysed whether the different adiponectin isoforms induce diverging effects, especially with regard to rheumatoid arthritis synovial fibroblasts (RASF), a central cell type in RA pathogenesis capable of invading into and destroying cartilage.METHODS: Affymetrix microarrays were used to screen for changes in gene expression of RASF. Messenger RNA levels were quantified by real-time PCR, protein levels by immunoassay. The migration of RASF and primary human lymphocytes was analysed using a two-chamber migration assay.RESULTS: In RASF, the individual adiponectin isoforms induced numerous genes/proteins relevant in RA pathogenesis to clearly different extents. In general, the most potent isoforms were the high molecular weight/middle molecular weight isoforms and the globular isoform, while the least potent isoform was the adiponectin trimer. The chemokines secreted by RASF upon adiponectin stimulation resulted in an increased migration of RASF and lymphocytes.CONCLUSION: The results clearly suggest a pro-inflammatory and joint-destructive role of all adiponectin isoforms in RA pathophysiology, indicating that in chronic inflammatory joint diseases the detrimental effects outweigh the beneficial effects of adiponectin.
\end{abstract}

DOI: https://doi.org/10.1136/annrheumdis-2011-200924

Posted at the Zurich Open Repository and Archive, University of Zurich

ZORA URL: https://doi.org/10.5167/uzh-62508

Journal Article

Originally published at:

Frommer, Klaus W; Schäffler, Andreas; Büchler, Christa; Steinmeyer, Jürgen; Rickert, Markus; Rehart, Stefan; Brentano, Fabia; Gay, Steffen; Müller-Ladner, Ulf; Neumann, Elena (2012). Adiponectin isoforms: a potential therapeutic target in rheumatoid arthritis? Annals of the Rheumatic Diseases, 71(10):17241732 .

DOI: https://doi.org/10.1136/annrheumdis-2011-200924 


\section{ADIPONECTIN ISOFORMS: A POTENTIAL THERAPEUTIC TARGET IN RHEUMATOID ARTHRITIS?}

Running Title: Differential effects of adiponectin isoforms on RASF

Klaus W. Frommer ${ }^{1}$, Andreas Schäffler ${ }^{2}$, Christa Büchler ${ }^{2}$, Jürgen Steinmeyer ${ }^{3}$, Markus Rickert ${ }^{4}$, Stefan Rehart ${ }^{5}$, Fabia Brentano ${ }^{6}$, Steffen Gay ${ }^{6}$, Ulf Müller-Ladner ${ }^{1}$, Elena Neumann ${ }^{1}$

${ }^{1}$ Department of Internal Medicine and Rheumatology, Justus-Liebig-University Gießen, Kerckhoff-Klinik, Bad Nauheim, Germany

2 Department of Internal Medicine I, University of Regensburg, Regensburg, Germany

${ }^{3}$ Department of Orthopedics and Experimental Orthopedics, University Hospital Gießen and Marburg, Gießen, Germany

${ }^{4}$ Justus-Liebig-University of Gießen, Orthopedics and Orthopedic Surgery, Gießen, Germany

${ }^{5}$ Department of Orthopedics and Trauma Surgery, St. Markus Hospital, Frankfurt, Germany

${ }^{6}$ Center for Experimental Rheumatology, University Hospital Zürich, Switzerland

\section{Corresponding Author and Request for Reprints:}

Elena Neumann, PhD

Department of Internal Medicine and Rheumatology

Justus-Liebig-University Gießen

Kerckhoff-Klinik

Benekestraße 2-8

D-61231 Bad Nauheim, Germany

Phone: +49-6032-996-2801, Fax: +49-6032-996-2809

E-mail: e.neumann@kerckhoff-klinik.de

Keywords: Rheumatoid Arthritis, Synovitis, Fibroblasts 


\section{ABSTRACT}

Objectives: Several clinical studies suggest the adipocytokine adiponectin is involved in the progression of rheumatoid arthritis (RA). From this point of view, adiponectin might present a new therapeutic target. However, as adiponectin also exerts beneficial effects in the human organism, a strategy that would allow its detrimental effects to be abolished while maintaining the positive effects would be highly favorable. To elucidate such a strategy, we analyzed whether the different adiponectin isoforms induce diverging effects, especially with regard to RA synovial fibroblasts (SF), a central cell type in RA pathogenesis capable of invading into and destroying cartilage.

Methods: Affymetrix microarrays were used to screen for changes in gene expression of RASF. mRNA levels were quantified by real-time PCR, protein levels by immunoassay. Migration of RASF and primary human lymphocytes was analyzed using a two-chamber migration assay.

Results: In RASF, the individual adiponectin isoforms induced numerous genes/proteins relevant in RA pathogenesis to clearly different extents. In general, the most potent isoforms were the high-molecular weight/middle-molecular weight isoforms and the globular isoform, while the least potent isoform was the adiponectin trimer. The chemokines secreted by RASF upon adiponectin stimulation resulted in an increased migration of RASF and lymphocytes.

Conclusion: Our results clearly suggest a pro-inflammatory and joint-destructive role of all adiponectin isoforms in RA pathophysiology, indicating that in chronic inflammatory joint diseases the detrimental effects outweigh the beneficial effects of adiponectin. 


\section{INTRODUCTION}

With $1 \%$ prevalence worldwide, rheumatoid arthritis (RA) is a common form of arthritis that - although the onset of RA is more frequent later in life - can affect people at any age. Without adequate treatment, this severe chronic inflammatory joint disease inevitably causes loss of articular function and mobility. Even though nowadays effective therapeutics are available against the progression of the disease, additional therapeutic options are still needed when current therapies fail or cause severe adverse effects. This is where the so-called adipocytokines may come into play.

The major source of adipocytokines is adipose tissue. It has now become evident that adipose tissue is not merely an immunologically inactive type of connective tissue but also an important immunoendocrine organ producing hormones and cytokines [1-3]. These factors have been collectively termed adipocytokines or - in short - adipokines. Adiponectin (Ad), leptin, resistin, and visfatin are just a few examples of this growing number of highly bioactive substances with metabolic and immunological functions [4, 5].

Pathologically, adipokines appear to be involved in numerous chronic inflammatory diseases. This not only includes rheumatoid arthritis (RA) but also systemic lupus erythematosus (SLE), ankylosing spondylitis (AS), and systemic sclerosis (SSc) [6].

Synovial hyperplasia accompanied by substantial inflammation and degradation of joints [7] is a key feature of RA, and RA synovial fibroblasts (SF) are a major player in these destructive processes [8-10]. This RA-specific cell type therefore presents a promising target for therapeutic intervention. For that reason, we investigated the effects of the adipocytokine adiponectin on RASF in order to find out how this may affect the pathogenesis of RA.

Adiponectin, a C1q/tumor necrosis factor (TNF) homolog [11], lent itself to this question as its synovial fluid levels are significantly increased in RA patients compared to osteoarthritis 
(OA) patients as well as healthy controls $[12,13]$ and hyperadiponectinemia is associated with an increased number of joint destructions [14] or radiographic progression $[15,16]$ in RA patients. Of note, adiponectin is not only produced by adipose tissue but also by synovial fibroblasts, endothelial cells, osteoblasts, and cardiac myocytes [17-19]. In a previous study [20], we could already show that native adiponectin affects several RA effector cells.

Interestingly, adiponectin is not a homogenous entity but consists of several isoforms corresponding to different oligomers with a "bouquet of flower" structure. Trimeric adiponectin, also called low-molecular weight (LMW) adiponectin, is composed of three fulllength adiponectin monomers forming a collagen triple helix with a $\mathrm{C}$-terminal globular $\mathrm{gC} 1 \mathrm{q}$ domain (head domain) [21]. Globular adiponectin (gAd) consists of the head domain of trimeric adiponectin as a result of proteolytic cleavage [22-24]. The adiponectin hexamer, the so-called middle-molecular weight (MMW) adiponectin, is a combination of two trimeric adiponectin molecules, while an assembly of 12 to 18 monomers is collectively termed high-molecular weight (HMW) adiponectin [21]. Even though some studies investigated selected adiponectin isoforms [21, 25-28], there have not yet been any studies analyzing potentially differential effects of adiponectin isoforms on effector cells involved in the pathophysiology of RA.

With adiponectin's important functions in energy metabolism and beneficial effects on the cardiovascular system [29, 30], it might be unadvisable to modulate adiponectin levels systemically in order to prevent its disease-promoting effects in RA. Instead, inhibiting adiponectin locally at sites of joint destruction or targeting specific isoforms could be viable options. Hence, in this study we investigated whether adiponectin isoforms differentially affect gene expression and protein secretion of RASF, and could thus provide targets for specifically inhibiting the detrimental effects of adiponectin while preserving its beneficial effects. As rheumatoid synovium is strongly infiltrated by lymphocytes and migrating RASF, 
which can additionally invade the synovium and cartilage [8], we also analyzed whether the factors induced by the different adiponectin isoforms in RASF have chemoattractive properties on RASF and lymphocytes. 


\section{MATERIALS \& METHODS}

\section{Cell culture}

Human primary synovial fibroblasts and primary lymphocytes were cultured as described within the supplementary material.

\section{Isolation of synovial fibroblasts}

Synovial tissue samples were obtained from synovial biopsy specimens from RA and OA patients who were undergoing joint surgery. All specimens were obtained with the approval of the Ethics Committee of the Justus-Liebig-University of Gießen. All patients gave informed consent and fulfilled the criteria of the American College of Rheumatology [31, 32]. Following enzymatic digestion [33, 34], primary synovial fibroblasts were isolated and cultured in supplemented DMEM as described previously [20].

\section{Isolation of lymphocytes from human whole blood}

Lymphocytes were isolated by Ficoll-based density gradient centrifugation as described in more detail within the supplementary material.

\section{Stimulation of RASF and OASF}

RASF and OASF from passages 3-8 were grown to 70-80\% confluency and stimulated with $25 \mu \mathrm{g} / \mathrm{ml}$ of different human adiponectin forms (BioVendor) for 15 hours: native adiponectin (= a mixture of different adiponectin isoforms; recombinantly produced in HEK 293 cells), HMW-/MMW-enriched adiponectin (recombinantly produced in HEK 293 cells), trimeric adiponectin (recombinantly produced in HEK 293 cells; prevented from further oligomerization by a single amino acid mutation), and globular adiponectin (recombinantly produced in E. coli). SDS-PAGE analysis images of the commercially available adiponectin 
preparations, which were used, are shown in Supplementary Figure S1. The stimulation time was chosen based on preliminary experiments that demonstrated optimal response after 15 hours [18]. Unstimulated RASF and OASF were used as negative controls. Dose-response analyses were performed previously [18] and showed that induction of IL-6 and pro-MMP1 by adiponectin does not reach a plateau until a concentration of approximately $100 \mu \mathrm{g} / \mathrm{ml}$. We additionally showed that potential LPS contaminations of recombinant adiponectin were not responsible for the effects observed after stimulation [20].

\section{Affymetrix gene chips}

RASF (passage $5 ; \mathrm{n}=1$ ) were stimulated for 15 hours with $25 \mu \mathrm{g} / \mathrm{ml}$ of the different adiponectin isoforms as described above. Affymetrix microarray analysis was performed as described within the supplementary material.

\section{Real-time polymerase chain reaction $(\mathrm{PCR})$}

Reverse transcription of RNA and real-time PCR were performed as described within the supplementary material.

\section{Immunoassays}

The cytokine, chemokine, MMP, and adiponectin levels in cell culture supernatants were measured using commercially available enzyme-linked immunosorbent assays (ELISAs) (R\&D Systems).

\section{Two-chamber migration assay}

Media from adiponectin-stimulated RASF were analyzed for their chemoattractive potential on RASF and lymphocytes using a two-chamber migration system. The procedure is described in detail within the supplementary material. 


\section{Statistical analysis}

Biological or experimental replicates were used to calculate arithmetic means and standard errors of the mean (SEM). Data are presented as the mean \pm SEM. In order to assess the significance of differences, a Student's 2-tailed t-test was performed for pairwise comparisons. For multiple comparisons, ANOVA including Tukey's post-hoc test was performed. $\mathrm{P}$ values $<0.05$ were considered significant. Statistical calculations were performed using Microsoft Excel and GraphPad Prism. 


\section{RESULTS}

\section{Differential induction of chemokines in RASF by adiponectin isoforms}

RASF are an RA-specific cell type capable of driving inflammation and joint destruction [9], of invading into cartilage [35], and of migrating from joint to joint [8]. Inhibiting their destructive activity is a desirable goal in RA therapy. Factors that promote or inhibit this activity are hence of substantial interest as potential therapeutic targets. We therefore analyzed the effects of the different adiponectin isoforms on RASF gene expression, focusing on finding out whether there are differences in the effects of the adiponectin isoforms and to which degree each isoform might be involved in RA pathogenesis.

First, Affymetrix microarray analysis (GeneChip HG U133A) was performed in order to compare the gene expression of RASF stimulated with the different adiponectin isoforms or RASF left unstimulated. As large amounts of mRNA are required for Affymetrix microarrays and patient material was limited, one RASF population $(n=1)$ was analyzed exemplarily in this experiment to screen for changes in gene expression. The variability of different RASF populations was later accounted for by verifying selected results with higher $\mathrm{n}$ numbers. Chemokines were the largest group of dysregulated genes and differentially induced by the adiponectin isoforms (Table 1). Verification of selected chemokines (GRO- $\alpha /-\beta /-\gamma$, ENA-78, GCP-2, MCP-1, MCP-3) by real-time PCR confirmed the differential induction of mRNA expression in multiple RASF populations (Table 2 and Figure 1A). Using immunoassays, we confirmed that chemokine secretion (GRO- $\alpha$, ENA-78, GCP-2, IL-8, MCP-1, RANTES) was also differentially regulated by the individual adiponectin isoforms (Table 3 and Figure 1B). I-TAC (CXCL11) and MIP-3 $\alpha$ (CCL20) protein, however, could not be detected in either cell culture supernatants or cell lysates (data not shown). Especially within the real-time PCR and immunoassay results, we could identify a distinct pattern regarding the effect of the different adiponectin isoforms on RASF: overall, HMW/MMW-enriched and globular adiponectin 
were the most potent isoforms, while the adiponectin trimer was the least effective. Native adiponectin, which has been not been enriched for any isoform, mostly held a middle ground but was rather variable in its potency depending on the regulated gene or protein. These observations are illustrated in Figure 1.

Differential induction of cytokines, matrix metalloproteinases (MMPs) and other RA-related genes in RASF by adiponectin isoforms

Not only chemokines, but also proinflammatory cytokines, matrix metalloproteinases and inflammation-related enzymes play a major role in RA pathogenesis. Their regulation is therefore crucial.

Our results showed that cytokines, MMPs and other RA-related molecules were also regulated to very different extents depending on the particular adiponectin isoform (Table 1 and 3, Figure 1B). For example, secretion of the proinflammatory cytokine IL-6 was most strongly induced by HMW/MMW-enriched adiponectin, while the weakest response was seen with trimeric adiponectin. Similar differential inductions by the individual adiponectin isoforms could be observed for the inflammation-related enzyme cyclooxygenase 2 (COX2) as well as the MMPs 1, 3, 10 and 12 .

\section{Biological variability of RASF cell populations in response to adiponectin stimulation}

Different RASF cell populations, i.e. SF obtained from different RA patients, showed highly variable responses to stimulation with adiponectin. Adiponectin upregulated gene expression or protein secretion in all cell populations that were analyzed but to very different extents, which is illustrated in Figure 2A. 


\section{Response of OASF to adiponectin stimulation in comparison to RASF}

SF from RA patients and OA patients responded similarly to stimulation with adiponectin isoforms but OASF generally showed a weaker mean response than RASF, demonstrating the special phenotype of RASF (Figure 2B). However, due to the high biological variability of the cell populations, statistical significance for the differences between RASF and OASF responses could not be reached in most cases. Although the differences in the response towards the different adiponectin isoforms were not as prominent as for RASF, differences could also be detected for OASF.

\section{Chemoattractive effect of adiponectin-induced factors on RASF and lymphocytes}

As outlined above, adiponectin isoforms induced numerous chemokines. We therefore investigated to which extent this leads to a functional chemoattractive effect on RASF and lymphocytes, two key cell types in RA. A two-chamber migration assay was performed with RASF and primary human lymphocytes. Conditioned media from RASF cultures incubated with the different adiponectin isoforms were used as potential chemoattractants against medium from unstimulated RASF incubated in parallel. RASF were allowed to migrate for 15 hours, lymphocytes for 4 hours. Cells that actively passed the membrane of the two-chamber migration system were counted. The gradient-free baseline was set to $100 \%$.

Here, we observed an increased migration for RASF and lymphocytes towards conditioned medium from adiponectin-stimulated RASF, indicating that the adiponectin-induced factors have a significant chemoattractive effect on RASF $(n=3)$ (Figure 3A) and lymphocytes $(n=3)$ (Figure 3B). Additional controls with adiponectin $(25 \mu \mathrm{g} / \mathrm{ml})$ added just prior to the start of the migration assay showed that adiponectin itself does not have any chemoattractive properties on the cell types analyzed (data not shown). 
In summary, factors induced by adiponectin isoforms had a differential effect on RASF and lymphocyte migration, thus reflecting the individual effects of the respective adiponectin isoforms on protein secretion by RASF. 


\section{DISCUSSION}

The primary objective of this study was to investigate if the different isoforms of the adipokine adiponectin have differential effects on RASF, a key cell type in RA pathogenesis. Previous data [14-16, 20] suggest that adiponectin may be rather detrimental in RA and involved in disease progression. However, since available data indicate that adiponectin is beneficial for metabolic and cardiovascular health [29, 30], systemic elimination in order to avoid the harmful effects in RA might not be a favorable option. Based on initial data [27, 28], researchers concluded that mainly HMW adiponectin is responsible for the vascularprotective effects of adiponectin. On the other hand, available data suggest that adiponectin promotes RA progression [14-16] and does this most likely by inducing the secretion of proinflammatory molecules (e.g. IL-6, COX-2), chemokines (e.g. IL-8, MCP-1) and matrixdegrading enzymes (e.g. MMP3) [20]. Adiponectin is thus able to mount and sustain a proinflammatory response in various pathophysiologically relevant cell types in RA and OA, including chondrocytes [20, 36, 37] and RASF [20], both of which share the common characteristics of mesenchymal-derived cells.

These results led to the hypothesis that inhibition of specific adiponectin isoforms might help circumvent the problem of reducing the harmful effects of adiponectin in RA while maintaining its beneficial effects. However, our results showed that even though the individual adiponectin isoforms have different potencies to modulate gene expression of RASF they do not have opposing effects or no effect at all in the setting of RA pathophysiology. Nonetheless, our results suggest that certain isoforms of adiponectin are more detrimental in RA than others. Therefore, when considering adiponectin as a progression or activity marker for RA, it may be best to look at the most potent isoforms.

With regard to functional aspects of adiponectin isoforms, we could show that adiponectininduced factors promote migration of RASF and lymphocytes in vitro, which in vivo may lead to increased synovial lymphocyte infiltration and additional influx of RASF to sites of 
inflammation and cartilage degradation. Inhibition of these processes by blocking the local effects of specific adiponectin isoforms within the joints could therefore lead to reduced disease progression and activity.

Another interesting observation was the high variability of RASF in response to adiponectin isoform stimulation, which may be attributed to different genetic profiles [38, 39] as well as epigenetic variations between RASF populations [40]. This is also in line with clinical findings showing that there are considerable differences in how RA patients respond to the different available medications. RASF possess a special phenotype reflected not only in their ability to migrate and invade into cartilage [8] but also in their ability to respond to external stimuli such as adiponectin, which was illustrated here by the weaker response of OASF to adiponectin compared to RASF.

When considering strategies for modulating the effects of adiponectin, there are other conceivable options besides modulating adiponectin itself: targeting adiponectin receptors [41-43] or co-receptors [44-47], and inhibiting the oligomerization of adiponectin isoforms by small molecule inhibitors that prevent the assembly into higher molecular weight isoforms.

With respect to animal models, the viability of adiponectin knock-out (KO) mice indicates that, at least in mice, adiponectin is not vital, but results regarding the effects of adiponectin knock-out or overexpression in vivo are controversial. While Shinoda et al. [48] found no abnormalities regarding bone mass and turnover in $\mathrm{Ad}^{-} / \mathrm{Ad}^{-}$mice, Williams et al. [49] as well as Oshima et al. [50] found an increased bone density. Conversely, adiponectin overexpressing mice had increased bone mass, parameters of bone resorption and bone erosion were not affected [51]. Contrary to what we would have expected based on our results, adenovirus-mediated systemic expression of human adiponectin in collagen-induced arthritis (CIA) mice reduced clinical disease activity scores of CIA [52]. Most likely, this result reflects the distinct phenotype of human RASF and the difference between human and murine arthritides. 
Several groups also analyzed the overexpression or knockdown of adiponectin in mouse models in the metabolic and vascular context [53-57]. Under special nutritional conditions (high-fat and/or high-glucose diet) or on an obesity background (ob/ob), anti-diabetic and anti-atherogenic properties were observed for overexpression of adiponectin, while adiponectin knockout resulted in insulin resistance and impaired glucose metabolism. Therefore, it is always important to consider the experimental environment when looking at the in vivo effects of adiponectin.

Also, as yet nothing is known about the role of adiponectin isoforms in mice, their occurrence and distribution. It therefore remains questionable to what extent the existing adiponectin $\mathrm{KO}$ mouse models are able to provide hints on how adiponectin isoform deprivation would affect human RA.

In conclusion, while adiponectin may present an interesting therapeutic target in RA, more research is required to elucidate whether adiponectin isoforms can be targeted specifically and respective inhibitors can be used to provide new therapeutic approaches. Nonetheless, the clearly different potencies of adiponectin isoforms in RA suggest that considering the isoforms may be of value when utilizing adiponectin as a marker for risk, activity or progression of RA.

\section{ACKNOWLEDGMENTS}

We thank Rosel Engel and Ümit Gürler for their excellent technical assistance and help. This work was supported by the German research society (NE1174/3-1), the FP 6 Autocure, FP7 Masterswitch and IAR Epalinges.

\section{LICENCE FOR PUBLICATION}

The Corresponding Author has the right to grant on behalf of all authors and does grant on behalf of all authors, an exclusive licence (or non exclusive for government employees) on a 
worldwide basis to the BMJ Publishing Group Ltd to permit this article (if accepted) to be published in ARD and any other BMJPGL products and sublicences such use and exploit all subsidiary rights, as set out in our licence

(http://group.bmj.com/products/journals/instructions-for-authors/licence-forms).

\section{COMPETING INTERESTS}

None declared. 


\section{REFERENCES}

1. Kim S, Moustaid-Moussa N. Secretory, endocrine and autocrine/paracrine function of the adipocyte. J Nutr 2000;130:3110S-5S.

2. Ronti T, Lupattelli G, Mannarino E. The endocrine function of adipose tissue: an update. Clin Endocrinol (Oxf) 2006;64:355-65.

3. Ushiyama T, Chano T, Inoue K, et al. Cytokine production in the infrapatellar fat pad: another source of cytokines in knee synovial fluids. Ann Rheum Dis 2003;62:108-12.

4. Muoio DM, Newgard CB. Metabolism: A is for adipokine. Nature 2005;436:337-8.

5. Tilg H, Moschen AR. Adipocytokines: mediators linking adipose tissue, inflammation and immunity. Nat Rev Immunol 2006;6:772-83.

6. Neumann E, Frommer KW, Vasile M, et al. Adipocytokines as driving forces in rheumatoid arthritis and related inflammatory diseases? Arthritis Rheum 2011;63:1159-69.

7. Schumacher HR, Jr., Bautista BB, Krauser RE, et al. Histological appearance of the synovium in early rheumatoid arthritis. Semin Arthritis Rheum 1994;23:3-10.

8. Lefevre S, Knedla A, Tennie C, et al. Synovial fibroblasts spread rheumatoid arthritis to unaffected joints. Nat Med 2009;15:1414-20.

9. Müller-Ladner U, Ospelt C, Gay S, et al. Cells of the synovium in rheumatoid arthritis. Synovial fibroblasts. Arthritis Res Ther 2007;9:223.

10. Neumann E, Lefevre S, Zimmermann B, et al. Rheumatoid arthritis progression mediated by activated synovial fibroblasts. Trends Mol Med 2010;16:458-68.

11. Shapiro L, Scherer PE. The crystal structure of a complement-1q family protein suggests an evolutionary link to tumor necrosis factor. Curr Biol 1998;8:335-8. 
12. Schäffler A, Ehling A, Neumann E, et al. Adipocytokines in synovial fluid. JAMA 2003;290:1709-10.

13. Otero M, Lago R, Gomez R, et al. Changes in plasma levels of fat-derived hormones adiponectin, leptin, resistin and visfatin in patients with rheumatoid arthritis. Ann Rheum Dis 2006;65:1198-201.

14. Ebina K, Fukuhara A, Ando W, et al. Serum adiponectin concentrations correlate with severity of rheumatoid arthritis evaluated by extent of joint destruction. Clin Rheumatol 2009;28:44551.

15. Giles JT, van der Heijde DM, Bathon JM. Association of circulating adiponectin levels with progression of radiographic joint destruction in rheumatoid arthritis. Ann Rheum Dis 2011;70:1562-8.

16. Klein-Wieringa IR, van der Linden MP, Knevel R, et al. Baseline serum adipokine levels predict radiographic progression in early rheumatoid arthritis. Arthritis Rheum 2011.

17. Berner HS, Lyngstadaas SP, Spahr A, et al. Adiponectin and its receptors are expressed in bone-forming cells. Bone 2004;35:842-9.

18. Ehling A, Schaffler A, Herfarth $\mathrm{H}$, et al. The potential of adiponectin in driving arthritis. $J$ Immunol 2006;176:4468-78.

19. Pineiro R, Iglesias MJ, Gallego R, et al. Adiponectin is synthesized and secreted by human and murine cardiomyocytes. FEBS Lett 2005;579:5163-9.

20. Frommer KW, Zimmermann B, Meier FM, et al. Adiponectin-mediated changes in effector cells involved in the pathophysiology of rheumatoid arthritis. Arthritis Rheum 2010;62:288699. 
21. Tsao TS, Murrey HE, Hug C, et al. Oligomerization state-dependent activation of NF-kappa B signaling pathway by adipocyte complement-related protein of $30 \mathrm{kDa}$ (Acrp30). J Biol Chem 2002;277:29359-62.

22. Fruebis J, Tsao TS, Javorschi S, et al. Proteolytic cleavage product of 30-kDa adipocyte complement-related protein increases fatty acid oxidation in muscle and causes weight loss in mice. Proc Natl Acad Sci U S A 2001;98:2005-10.

23. Hattori Y, Hattori S, Akimoto K, et al. Globular adiponectin activates nuclear factor-kappaB and activating protein-1 and enhances angiotensin II-induced proliferation in cardiac fibroblasts. Diabetes 2007;56:804-8.

24. Waki H, Yamauchi T, Kamon J, et al. Generation of globular fragment of adiponectin by leukocyte elastase secreted by monocytic cell line THP-1. Endocrinology 2005;146:790-6.

25. Hattori Y, Nakano Y, Hattori S, et al. High molecular weight adiponectin activates AMPK and suppresses cytokine-induced NF-kappaB activation in vascular endothelial cells. FEBS Lett 2008;582:1719-24.

26. Haugen F, Drevon CA. Activation of nuclear factor-kappaB by high molecular weight and globular adiponectin. Endocrinology 2007;148:5478-86.

27. Kobayashi H, Ouchi N, Kihara S, et al. Selective suppression of endothelial cell apoptosis by the high molecular weight form of adiponectin. Circ Res 2004;94:e27-31.

28. Tomizawa A, Hattori Y, Kasai K, et al. Adiponectin induces NF-kappaB activation that leads to suppression of cytokine-induced NF-kappaB activation in vascular endothelial cells: globular adiponectin vs. high molecular weight adiponectin. Diab Vasc Dis Res 2008;5:123-7.

29. Beltowski J, Jamroz-Wisniewska A, Widomska S. Adiponectin and its role in cardiovascular diseases. Cardiovasc Hematol Disord Drug Targets 2008;8:7-46. 
30. Shibata R, Ouchi N, Murohara T. Adiponectin and cardiovascular disease. Circ J 2009;73:608-14.

31. Altman R, Asch E, Bloch D, et al. Development of criteria for the classification and reporting of osteoarthritis. Classification of osteoarthritis of the knee. Diagnostic and Therapeutic Criteria Committee of the American Rheumatism Association. Arthritis Rheum 1986;29:103949.

32. Arnett FC, Edworthy SM, Bloch DA, et al. The American Rheumatism Association 1987 revised criteria for the classification of rheumatoid arthritis. Arthritis Rheum 1988;31:315-24.

33. Neumann E, Judex M, Kullmann F, et al. Inhibition of cartilage destruction by double gene transfer of IL-1Ra and IL-10 involves the activin pathway. Gene Ther 2002;9:1508-19.

34. Neumann E, Kullmann F, Judex M, et al. Identification of differentially expressed genes in rheumatoid arthritis by a combination of complementary DNA array and RNA arbitrarily primed-polymerase chain reaction. Arthritis Rheum 2002;46:52-63.

35. Müller-Ladner U, Kriegsmann J, Franklin BN, et al. Synovial fibroblasts of patients with rheumatoid arthritis attach to and invade normal human cartilage when engrafted into SCID mice. Am J Pathol 1996;149:1607-15.

36. Gomez R, Scotece M, Conde J, et al. Adiponectin and leptin increase IL-8 production in human chondrocytes. Ann Rheum Dis 2011;70:2052-4.

37. Lago R, Gomez R, Otero M, et al. A new player in cartilage homeostasis: adiponectin induces nitric oxide synthase type II and pro-inflammatory cytokines in chondrocytes. Osteoarthritis Cartilage 2008;16:1101-9.

38. Huber R, Hummert C, Gausmann U, et al. Identification of intra-group, inter-individual, and gene-specific variances in mRNA expression profiles in the rheumatoid arthritis synovial membrane. Arthritis Res Ther 2008;10:R98. 
39. Kasperkovitz PV, Timmer TC, Smeets TJ, et al. Fibroblast-like synoviocytes derived from patients with rheumatoid arthritis show the imprint of synovial tissue heterogeneity: evidence of a link between an increased myofibroblast-like phenotype and high-inflammation synovitis. Arthritis Rheum 2005;52:430-41.

40. Karouzakis E, Gay RE, Gay S, et al. Epigenetic control in rheumatoid arthritis synovial fibroblasts. Nat Rev Rheumatol 2009;5:266-72.

41. Kadowaki T, Yamauchi T. Adiponectin and adiponectin receptors. Endocr Rev 2005;26:43951.

42. Tan W, Wang F, Zhang M, et al. High Adiponectin and Adiponectin Receptor 1 Expression in Synovial Fluids and Synovial Tissues of Patients with Rheumatoid Arthritis. Semin Arthritis Rheum 2008.

43. Yamauchi T, Kamon J, Ito Y, et al. Cloning of adiponectin receptors that mediate antidiabetic metabolic effects. Nature 2003;423:762-9.

44. Charlton HK, Webster J, Kruger S, et al. ERp46 binds to AdipoR1, but not AdipoR2, and modulates adiponectin signalling. Biochem Biophys Res Commun 2010;392:234-9.

45. Heiker JT, Wottawah CM, Juhl C, et al. Protein kinase CK2 interacts with adiponectin receptor 1 and participates in adiponectin signaling. Cell Signal 2009;21:936-42.

46. Hug C, Wang J, Ahmad NS, et al. T-cadherin is a receptor for hexameric and high-molecularweight forms of Acrp30/adiponectin. Proc Natl Acad Sci U S A 2004;101:10308-13.

47. Mao X, Kikani CK, Riojas RA, et al. APPL1 binds to adiponectin receptors and mediates adiponectin signalling and function. Nat Cell Biol 2006;8:516-23.

48. Shinoda Y, Yamaguchi M, Ogata N, et al. Regulation of bone formation by adiponectin through autocrine/paracrine and endocrine pathways. J Cell Biochem 2006;99:196-208. 
49. Williams GA, Wang Y, Callon KE, et al. In vitro and in vivo effects of adiponectin on bone. Endocrinology 2009;150:3603-10.

50. Oshima K, Nampei A, Matsuda M, et al. Adiponectin increases bone mass by suppressing osteoclast and activating osteoblast. Biochem Biophys Res Commun 2005;331:520-6.

51. Mitsui Y, Gotoh M, Fukushima N, et al. Hyperadiponectinemia enhances bone formation in mice. BMC Musculoskelet Disord 2011;12:18.

52. Ebina K, Oshima K, Matsuda M, et al. Adenovirus-mediated gene transfer of adiponectin reduces the severity of collagen-induced arthritis in mice. Biochem Biophys Res Commun 2009;378:186-91.

53. Kim JY, van de Wall E, Laplante M, et al. Obesity-associated improvements in metabolic profile through expansion of adipose tissue. J Clin Invest 2007;117:2621-37.

54. Maeda N, Funahashi T. [Adiponectin knockout mice]. Nippon Rinsho 2004;62:1067-76.

55. Matsuzawa Y, Shimomura I, Kihara S, et al. Importance of adipocytokines in obesity-related diseases. Horm Res 2003;60 Suppl 3:56-9.

56. Nawrocki AR, Rajala MW, Tomas E, et al. Mice lacking adiponectin show decreased hepatic insulin sensitivity and reduced responsiveness to peroxisome proliferator-activated receptor gamma agonists. J Biol Chem 2006;281:2654-60.

57. Okamoto Y, Kihara S, Ouchi N, et al. Adiponectin reduces atherosclerosis in apolipoprotein E-deficient mice. Circulation 2002;106:2767-70. 


\section{FIGURE LEGENDS}

\section{Figure 1.}

(A) Differential induction of chemokine mRNA expression in RASF by adiponectin isoforms (real-time PCR data). Multiple RASF populations $(\mathrm{n}=4)$ were stimulated with adiponectin isoforms or left unstimulated (control). x-fold changes in mRNA expression of several chemokines were determined by real-time PCR and are shown (as arithmetic mean) in comparison for all adiponectin isoforms used for stimulation.

(B) Differential induction of cytokine, chemokine and matrix metalloproteinase (MMP) secretion by RASF upon stimulation with adiponectin isoforms. Multiple RASF populations ( $n=4-15$, cf. Table 3) were stimulated with adiponectin isoforms or left unstimulated (control). x-fold changes in protein secretion of cytokines, chemokines and MMPs were determined by ELISA and are shown (as arithmetic mean) in comparison for all adiponectin isoforms used for stimulation.

\section{Figure 2.}

(A) Biological variability of RASF cell populations in response to adiponectin stimulation. Chemokine (ENA-78 and IL-8), cytokine (IL-6) and matrix metalloproteinase (MMP3) secretion was quantified by ELISA after adiponectin stimulation of cultured RASF from different RA patients. To illustrate the biological variability of RASF populations in response to adiponectin stimulation, the individual results ( $\mathrm{x}$-fold changes in protein secretion) are shown as dots. The arithmetic mean is displayed as a bar.

(B) Response of OASF to adiponectin stimulation in comparison to RASF. Multiple OASF populations ( $\mathrm{n}=4$ for GRO- $\alpha$; $\mathrm{n}=12$ for GCP-2; $\mathrm{n}=4$ for RANTES; $\mathrm{n}=12$ for MCP-1 / native Ad and $n=8$ for MCP-1 / other Ad) were stimulated with adiponectin isoforms in parallel to multiple RASF populations (cf. Table 3 for n numbers). Chemokine secretion was quantified by ELISA. Black bars indicate $\mathrm{x}$-fold changes in protein secretion for RASF, while white bars 
indicate $\mathrm{x}$-fold changes in protein secretion for OASF (each compared to unstimulated controls). Data are shown as the mean \pm SEM.

\section{Figure 3.}

(A) Chemoattractive effect of adiponectin-induced factors on RASF. Medium from RASF stimulated with different adiponectin isoforms was used in a two-chamber migration assay as a chemoattractant for RASF $(n=3)$. The baseline (without chemotactic gradient) was set to $100 \%$. Migration of RASF is expressed relative to the baseline. Using serum-free medium as a chemorepellent decreased RASF migration to $38 \%$, while using $10 \%$ FCS medium as a positive control increased RASF migration by $278 \%$ (data not shown).

(B) Chemoattractive effect of adiponectin-induced factors on lymphocytes. Medium from RASF stimulated with different adiponectin isoforms was used in a two-chamber migration assay as a chemoattractant for lymphocyte $(n=3)$ and analyzed as described above. Using serum-free medium as a chemorepellent decreased lymphocyte migration to $35 \%$, while using RANTES (10 ng/ml) + SDF (100 ng/ml) as a positive control increased lymphocyte migration by $345 \%$ (data not shown).

Data are shown as the mean \pm SEM. ${ }^{*} \mathrm{p}<0.05 ; * * \mathrm{p}<0.01 ; * * * \mathrm{p}<0.001$ 


\section{Table I Affymetrix microarray results: Differential gene induction in RASF by adiponectin isoforms}

\begin{tabular}{cccccc}
\hline Gene Name & $\begin{array}{c}\text { Gene } \\
\text { Symbol }\end{array}$ & $\begin{array}{c}\text { Fold } \\
\text { Change } \\
\text { Native Ad }\end{array}$ & $\begin{array}{c}\text { Fold } \\
\text { Change Ad } \\
\text { HMW/MMW }\end{array}$ & $\begin{array}{c}\text { Fold } \\
\text { Change } \\
\text { Ad Trimer }\end{array}$ & $\begin{array}{c}\text { Fold } \\
\text { Change } \\
\text { gAd }\end{array}$ \\
\hline
\end{tabular}

\section{Chemokines}

Chemokine (C-C motif) ligand 2 (CCL2)

Chemokine (C-C motif) ligand 5 (CCL5)

Chemokine (C-C motif) ligand 7 (CCL7)

Chemokine (C-C motif) ligand 8 (CCL8)

Chemokine (C-C motif) ligand 20 (CCL20)

Chemokine (C-X-C motif) ligand 1 (CXCL1)

Chemokine (C-X-C motif) ligand 2 (CXCL2)

Chemokine (C-X-C motif) ligand 3 (CXCL3)

Chemokine (C-X-C motif) ligand 5 (CXCL5)

Chemokine (C-X-C motif) ligand 6 (CXCL6)

Chemokine (C-X-C motif) ligand 8 (CXCL8)

Chemokine (C-X-C motif) ligand 9 (CXCL9)

Chemokine (C-X-C motif) ligand 10 (CXCL10)

Chemokine (C-X-C motif) ligand 11 (CXCL11)

$\begin{array}{cc}\text { MCP-1 } & 4.8 \\ \text { RANTES } & 24.0 \\ \text { MCP-3 } & 101.3 \\ \text { MCP-2 } & 25.8 \\ \text { MIP-3 } \alpha & 1424.0 \\ \text { GRO- } \alpha & 29.4 \\ \text { GRO- } \beta & 33.5 \\ \text { GRO- } & 99.6 \\ \text { ENA-78 } & 37.8 \\ \text { GCP-2 } & 5.5 \\ \text { IL-8 } & 43.4 \\ \text { MIG } & 9.3 \\ \text { IP-10 } & 161.0 \\ \text { I-TAC } & 130.9\end{array}$

4.7

24.7

74.9

11.2

1547.0

33.3

43.9

234.0

121.7

5.6

50.5

36.7

78.6

88.0

6.5

441.0

6.6

157.4

8.9

IL-11

24.3

3.4

4.6

2.4

9.4

PTGS2/

COX2

19.9

17.9

7.1

26.1

cyclooxygenase 2

\section{Pre-B-Cell Growth \& B-Cell Activation}

Bone marrow stromal cell antigen 2

BST2

200.8

100.4

28.0

1091.0

\section{Receptors}

Interleukin 7 receptor

Interleukin 17 receptor $B$

\section{IL7R}

IL17RB

5.6

2.6

6.9

2.1

3.0

1.0

8.9

2.8

\section{Proteinases \& Peptidases}

Matrix metallopeptidase 1 (interstitial collagenase)

Matrix metallopeptidase 3 (stromelysin 1

progelatinase)

Matrix metallopeptidase 10 (stromelysin 2)

Matrix metallopeptidase 12 (macrophage

elastase)

MMP1
MMP3
MMP10

MMP12

STC1

FGF10
11.6

62.5

88.7

49.9

19.8

5.0

5.6

1.0

3.9

RASF $(n=1)$ were treated with adiponectin isoforms or left untreated (control). Affymetrix microarray analysis (GeneChip HG U133A) was performed as described. The results indicate that genes from several functional groups are differentially regulated in RASF by adiponectin isoforms. The cut-off value for fold changes was $\leq-2$ (repression) or $\geq 2$ (induction), respectively. Strongly repressed genes were low in number and of no known or well defined function. 
Table II Differentially induced chemokine mRNA expression in RASF by adiponectin isoforms

\begin{tabular}{|c|c|c|c|c|c|c|}
\hline Gene Name & Symbol & $\begin{array}{c}\text { Ad } \\
\text { Isoform }\end{array}$ & $\begin{array}{c}\text { Fold } \\
\text { Change }\end{array}$ & SEM & $\mathbf{n}$ & $\mathbf{p}$ \\
\hline Chemokine (C-X-C motif) ligand 1 (CXCL1) & GRO- $\alpha$ & $\begin{array}{c}\text { native } \\
\text { HMW/MMW } \\
\text { trimer } \\
\text { globular }\end{array}$ & $\begin{array}{c}23.9 \\
148.0 \\
14.1 \\
206.8\end{array}$ & $\begin{array}{c}8.9 \\
85.4 \\
8.1 \\
134.9\end{array}$ & $\begin{array}{l}4 \\
4 \\
4 \\
4\end{array}$ & $\begin{array}{l}0.036 \\
0.009 \\
0.021 \\
0.009\end{array}$ \\
\hline Chemokine (C-X-C motif) ligand 1 (CXCL2) & GRO- $\beta$ & $\begin{array}{c}\text { native } \\
\text { HMW/MMW } \\
\text { trimer } \\
\text { globular }\end{array}$ & $\begin{array}{c}23.3 \\
106.2 \\
9.3 \\
121.1\end{array}$ & $\begin{array}{c}8.0 \\
57.5 \\
4.5 \\
68.8\end{array}$ & $\begin{array}{l}4 \\
4 \\
4 \\
4\end{array}$ & $\begin{array}{l}0.054 \\
0.008 \\
0.021 \\
0.008\end{array}$ \\
\hline Chemokine (C-X-C motif) ligand 1 (CXCL3) & GRO-y & $\begin{array}{c}\text { native } \\
\text { HMW/MMW } \\
\text { trimer } \\
\text { globular }\end{array}$ & $\begin{array}{c}66.3 \\
77.7 \\
4.9 \\
33.3\end{array}$ & $\begin{array}{c}50.8 \\
36.7 \\
1.9 \\
13.4\end{array}$ & $\begin{array}{l}4 \\
4 \\
4 \\
4\end{array}$ & $\begin{array}{l}0.020 \\
0.005 \\
0.072 \\
0.008\end{array}$ \\
\hline Chemokine (C-X-C motif) ligand 5 (CXCL5) & ENA-78 & $\begin{array}{c}\text { native } \\
\text { HMW/MMW } \\
\text { trimer } \\
\text { globular }\end{array}$ & $\begin{array}{c}70.8 \\
57.7 \\
3.8 \\
22.2\end{array}$ & $\begin{array}{c}41.9 \\
24.7 \\
0.6 \\
8.4\end{array}$ & $\begin{array}{l}4 \\
4 \\
4 \\
4\end{array}$ & $\begin{array}{l}0.006 \\
0.002 \\
0.002 \\
0.054\end{array}$ \\
\hline Chemokine (C-X-C motif) ligand 6 (CXCL6) & GCP-2 & $\begin{array}{c}\text { native } \\
\text { HMW/MMW } \\
\text { trimer } \\
\text { globular }\end{array}$ & $\begin{array}{c}112.0 \\
584.6 \\
22.3 \\
410.2\end{array}$ & $\begin{array}{c}45.7 \\
327.7 \\
14.8 \\
233.7\end{array}$ & $\begin{array}{l}4 \\
4 \\
4 \\
4\end{array}$ & $\begin{array}{l}0.019 \\
0.003 \\
0.025 \\
0.003\end{array}$ \\
\hline Chemokine (C-C motif) ligand 2 (CCL2) & MCP-1 & $\begin{array}{c}\text { native } \\
\text { HMW/MMW } \\
\text { trimer } \\
\text { globular }\end{array}$ & $\begin{array}{c}7.2 \\
11.9 \\
2.7 \\
57.9\end{array}$ & $\begin{array}{c}1.9 \\
3.0 \\
0.5 \\
20.2\end{array}$ & $\begin{array}{l}4 \\
4 \\
4 \\
4\end{array}$ & $\begin{array}{l}0.008 \\
0.005 \\
0.013 \\
0.005\end{array}$ \\
\hline Chemokine (C-C motif) ligand 7 (CCL7) & MCP-3 & $\begin{array}{c}\text { native } \\
\text { HMW/MMW } \\
\text { trimer } \\
\text { globular }\end{array}$ & $\begin{array}{c}16.3 \\
17.8 \\
3.9 \\
56.1\end{array}$ & $\begin{array}{c}9.1 \\
7.9 \\
2.4 \\
38.1\end{array}$ & $\begin{array}{l}4 \\
4 \\
4 \\
4\end{array}$ & $\begin{array}{l}0.015 \\
0.007 \\
0.151 \\
0.077\end{array}$ \\
\hline
\end{tabular}

Multiple populations of RASF $(n=4)$ were stimulated with different adiponectin isoforms. RNA was isolated, reverse transcribed to CDNA and quantified by real-time PCR. Fold changes in mRNA expression (as compared to an unstimulated control), biological variability indicated by the standard error of mean (SEM), number of populations analyzed $(n)$, and the $p$-values are presented. 
Table III Differentially induced cytokine, chemokine and MMP secretion in RASF by adiponectin isoforms

\section{Protein Name}

Symbol

$\begin{array}{ccc}\begin{array}{c}\text { Ad } \\ \text { soform }\end{array} & \begin{array}{c}\text { Fold } \\ \text { Change }\end{array} & \text { SEM }\end{array}$

n

p

\section{Chemokines}

Chemokine (C-X-C motif) ligand 1 (CXCL1)

Chemokine (C-X-C motif) ligand 5 (CXCL5)
Chemokine (C-X-C motif) ligand 6 (CXCL6)
Chemokine (C-X-C motif) ligand 8 (CXCL8)
Chemokine (C-C motif) ligand 2 (CCL2)
Chemokine (C-C motif) ligand 5 (CCL5)

GRO- $\alpha$
ENA-78

$\begin{array}{cc}\text { native } & 125.1 \\ \text { HMW/MMW } & 150.9 \\ \text { trimer } & 19.0 \\ \text { globular } & 75.8\end{array}$

43.0

\section{9}

0.024

12.5

0.023

native 22.5

$\begin{array}{cc}\text { HMW/MMW } & 29.5 \\ \text { trimer } & 9.9\end{array}$

26.4

0.223

$\begin{array}{cc}\text { trimer } & 9.9 \\ \text { globular } & 14.8\end{array}$

6.2

0.027

globular $\quad 14.8$

5.4

0.005

$\begin{array}{lll}6.4 & 8 & 0.001\end{array}$

$\begin{array}{lll}3.9 & 8 & 0.056\end{array}$

$\begin{array}{lll}3.9 & 8 & 0.056 \\ 5.2 & 8 & 0.033\end{array}$

GCP-2

$\begin{array}{cc}\text { native } & 58.5 \\ \text { HMW/MMW } & 164.1 \\ \text { trimer } & 22.8\end{array}$

$\begin{array}{lll}23.1 & 15 & 0.026\end{array}$

globular $\quad 110.3 \quad 35.8$

0.009

$\begin{array}{llllll}\text { IL-8 } & \text { native } & 611.3 & 193.2 & 14 & 0.008\end{array}$

$\begin{array}{cll}\text { native } & 611.3 & 193.2 \\ \text { HMW/MMW } & 953.2 & 275.0\end{array}$

0.004

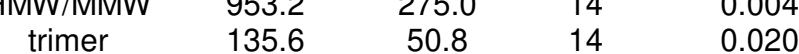

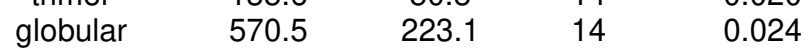

$\begin{array}{cccccc}\text { MCP-1 } & \text { native } & 15.8 & 3.6 & 13 & 0.001 \\ & \text { HMW/MMW } & 23.0 & 4.15 & 8 & 0.001\end{array}$

$\begin{array}{lllll}\text { trimer } & 17.2 & 7.9 & 8 & 0.081\end{array}$

$\begin{array}{lllll}\text { globular } & 18.5 & 6.9 & 8 & 0.040\end{array}$

RANTES

native $\quad 44.4$

\section{1}

$\begin{array}{lll}\text { HMW/MMW } & 77.5 & 17.8\end{array}$

0.127

trimer $\quad 10.0$

$\begin{array}{cc}\text { trimer } & 10.0 \\ \text { globular } & 145.3\end{array}$

35.6

0.381

\section{Cytokines}

Activin A

INHBA

$\begin{array}{cc}\text { native } & 15.1 \\ \text { HMW/MMW } & 32.0 \\ \text { trimer } & 7.3 \\ \text { globular } & 2.8 \\ \text { native } & 31.2 \\ \text { HMW/MMW } & 57.0 \\ \text { trimer } & 20.7 \\ \text { globular } & 26.8\end{array}$

$$
6.0
$$

Interleukin 6

IL-6

\section{7}

0.010

$\begin{array}{lll}16.9 & 12 & 0.007\end{array}$

$\begin{array}{lll}7.1 & 12 & 0.019\end{array}$

$\begin{array}{lll}9.9 & 12 & 0.024\end{array}$

\section{Proteinases \& Peptidases}

Matrix metallopeptidase 1, propeptide

pro-MMP1

$\begin{array}{cr}\text { native } & 11.9 \\ \text { HMW/MMW } & 24.4\end{array}$

8.1

15.9

trimer

globular

8.2
6.5

Matrix metallopeptidase 3

MMP3

native

10.3

HMW/MMW $\quad 19.2$

trimer $\quad 4.3$

globular

12.6

5.1

0.206

0.014

0.185

$\begin{array}{lll}3.5 & 10 & 0.025\end{array}$

$\begin{array}{lll}4.1 & 8 & 0.001\end{array}$

$\begin{array}{lll}1.5 & 8 & 0.063\end{array}$

$\begin{array}{lll}3.8 & 8 & 0.014\end{array}$

Matrix metallopeptidase 10

MMP10

$\begin{array}{cc}\text { native } & 4.4 \\ \text { HMW/MMW } & 11.6 \\ \text { trimer } & 2.7 \\ \text { globular } & 4.7\end{array}$

1.1
2.1
0.5
1.5

0.009

0.002

0.006

0.043

Multiple populations of RASF $(n=4-15)$ were stimulated with different adiponectin isoforms. Secreted chemokines, cytokines, and matrix metalloproteinases were quantified by immunoassays. Fold changes of secretion (as compared to an unstimulated control), biological variability indicated by the standard error of mean (SEM), number of populations analyzed $(n)$, and the $p$-values are presented. 